\title{
Valutastabilisering og Luksustold i 1810.
}

Af Gerda Selmer.

I.

For et Par Aar siden fandtes der $i$ en Avis et Indlæg i Diskussionen om det virksomste Middel til Stabilisering af Kronen, hvori der bragtes et Forslag frem for Offentligheden om Betimeligheden af ved Lov at hindre Udenlandsrejsende i at udføre over Grænsen mere, end et nærmere angivet minimalt Beløb i rede Penge.

At Tanken ikke er ny, ved vi. Det er kun nogle faa Aar siden, Tyskland vaagede omhyggeligt over, at Marken ikke fandt andre Veje at flygte bort ad, end de hjemlige Stier. Men at man allerede saa tidligt som i 1810 efter Krigen med Englænderne greb til dette Middel for at fæstne og forbedre vor Valuta, turde maaske være mindre velbekendt.

Ikke destomindre er det saadan, at Regeringen ogsaa den Gang fandt sig beføjet til at søge Udveje til at værge sig mod den omsiggribende landsskadelige Valutaflugt, ligesom den - som det skete nu igen - lagde Told paa indførte Luksusvarer, ja endog gik saa vidt at medregne Kaffe, The og Sukker til disse.

Lad os først se lidt paa denne Toldforordning eller Toldlov, om man vil.

"Vi Frederikden Siet te, a f G u d $\mathrm{Na}$ ade Kongetil Danmarkog Norge,deVenders og Gothers, Hertugtilslesvig, Holsten, 
Stormarn, Ditmarsken og oldenborg, Giøre vitterligt: Ligesom vi under.20de dennes have for Vore Hertugdomme paabudet en Afgivt af visse Colonialvarer, saaledes anordne og paabyde Vi herved en lignende Afgivt for vore Kiger Danmark og Norge; til hvilken Hensigt følgende ere Vore allerhøjeste Bestemmelser:

\section{§ 1.}

Naar nogen af de Varesorter, som nedenstaaende Tarif indeholder, nu befindes i Vore Riger uden at være inclarerede, da skal deraf i Stedet for de hidtil befalede Told- og Consumtionsafgivter svares det fulde Beløb af den i samme Tarif anførte Afgivt.

Dette sanıme gjelder om de Varer, som herefter ifølge Confiscation eller Condemnation indgaa.

$\$ 2$.

Forsaavidt bemeldte Varesorter for Ienne Vor allerhøjeste Anordnings Bekjendtgjørelse maatte vare inclarerede og nu forefindes i Vore Riger, da skal deraf svares det halve Beløb af den i 3aje $\$$ anforte Afgivt.

Naar Forraadet af en afgivtspligtig Varesort er saa lidet, at den Afgivt, som deraf bør svares, ikke fuldkommen beløber sig til 5 Rigsclaler, ville Vi allernaadigst have saalant Forraad frietaget for den $i$ denne $\$$ paabudne Afgift.

\section{$\$ 3$.}

Tarif.

Bontuld .............. for 1 Pund 40 sk. Raae sukker ............ »1 " 30 " Hvide dakkede og raffinerede Sukkere $\ldots \ldots \ldots \ldots \ldots \ldots$ " 1 " 40 " 
Thebohe, Congo, Campoi ..... » 1 » 15 Sk. Haysan, Peko ............ »1 1 " 60 "

Finere Thesorter s. Tschye,

Soulong $\ldots \ldots \ldots \ldots \ldots \ldots \ldots$ » 1 » 90 "

Caffe $\ldots \ldots \ldots \ldots \ldots \ldots \ldots \ldots \ldots$ » 1 " 40 »

Indigo $\ldots \ldots \ldots \ldots \ldots \ldots \ldots \ldots \ldots$ " 1 " 90 »

Cacao $\ldots \ldots \ldots \ldots \ldots \ldots \ldots \ldots \ldots$ " 1 " 101 "

Cochenille $\ldots \ldots \ldots \ldots \ldots \ldots \ldots \ldots$ " 1 " 202 "

Hvid Peber $\ldots \ldots \ldots \ldots \ldots \ldots \ldots$ » 1 " 60 »

Sort Peber..$\ldots \ldots \ldots \ldots \ldots \ldots \ldots$ » 1 » 40 »

Cassia Lignea ............ " I " 141 "

Agte Caneel ............ "

Nilliker $\ldots \ldots \ldots \ldots \ldots \ldots \ldots \ldots$ \# 1 » 60 "

Muscat .................. "1 " 202 »

Mahagonitræe $\ldots \ldots \ldots \ldots \ldots \ldots$ \# 1 " 5 »

Fernambuktræe $\ldots \ldots \ldots \ldots \ldots$ " 1 " 12 "

Campischetræe $\ldots \ldots \ldots \ldots \ldots \ldots$ » 1 » 8 »

Malet Farvetræe $\ldots \ldots \ldots \ldots \ldots$ » 1 » 10 "

$\S 4$.

Enhver, der har de i foranførte Tarif specificerede Varer i sin Værge enten sig selv eller andre tilhørende $i$ den Mængde, at deraf bor erlægges Afgivt, skal skrivtligen anmelde, hvilke og hvormange af de benævnte Varer, han er i Besiddelse af eller har i sin Værge.

Denne Anmeldelse, som skal skee paa den Maade, der nærmere af velkommende Øvrighed bestemmes, afgives:

for Kjøbenhavn og Helsingør til de af Os paa disse Steder anordnede Commissioner til at undersøge indførte Varers Neutralitet, inden 2 Gange 24 Timers Forløb efter denne vor Anordnings Bekjendtgjorelse; 
for de andre Kjøbstæder til Stedets Øvrighed og Toldembedsmænd inden 24 Timer efter Bekjendtgjørelsen;

for Landboerne til den Øvrighedsperson, som Amtmanden dertil udnævner, inden 3 Gange 24 Timer efter Anordningens Bekjendtgjørelse.

$\S 5$.

Afgivten skal i hvert Distrikt oppebæres af Toldvasenets Oppebørselsbetjente.

$\$ 6$.

De Varer, som efter deres Beskaffenhed og Mængde skulle belægges med Afgivten, men ikke dertil rigtigen er angivne, forfalde til Confiscation, og Angiveren af saadanne fordulgte Varer erholder det halve Beløb af Varernes Værdi til Belønning.

Hvorefter alle Vedkommende sig allerunderdanigst have at rette.

Givet paa Vort Slot Frederiksberg, d. 27. October 1810.

Under Vor Kongelige Haand og Segl Frederik R.

Den ovenfor omtalte

"Forordning angaaende en Afgivt af Colonialvare i Hertugdømmene«, lyder saaledes:

Vi Frederik den Siette, af Guds Naade, Konge til Dalrmark og Norge etc. gjøre vitterligt: At ligesom vi under Dags Dato have ved en anden Forordning allernaadigst bestemt under hvilke Betingelser de $\mathbf{i}$ det Kejserlige franske Dekret af 4 de d. Maaned benævnte Varer maa udføres fra Hertugdømmene til

- og igjennem Hamborg, saaledes bliver ogsaa herved anordnet og fastsat, at for nedenstaaende Varesorter, som nu befindes i Hertugdømmene og ikke bestem. 
mes til Forsendelse til Hamborg, eller som herefter indkomme ved Confiscation eller Opbringelse, skal følgende Afgivt udredes i Slesvig-holstensk Curant:

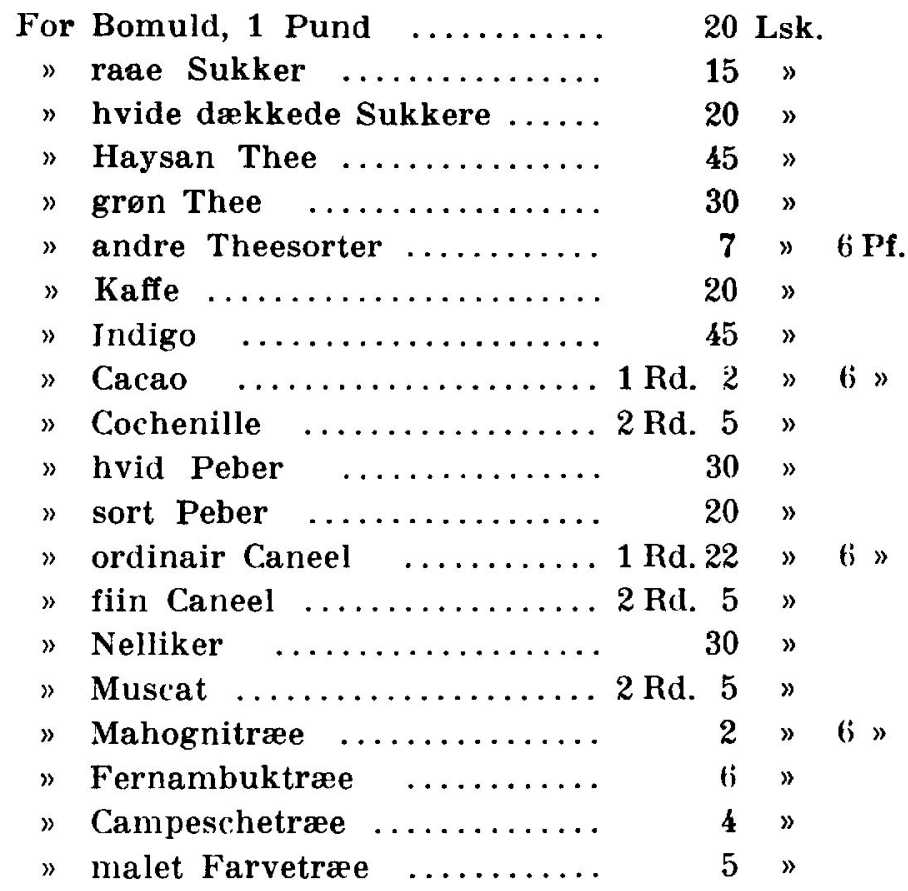

Foruden denne Afgivt skal ogsaa efter 8 \& $\mathrm{i}$ førnævinte Forordning af de Varer, som nu ere i Hertugdommene og ikke bestemmes til Forsendelse til Hamborg, erlægges $1 / 10$ af Afgivtens Beløb.

Denne Afgivt skal oppebæres af Toldforvalteren paa Stedet, og enhver Handling til Afgivtens Besvigelse har Varernes Confiscation og andre Straffe, som i Vor Toldforordning af 8 . Julii 1803 ere fastsatte for Toldsviig, til Følge. 
Hvorefter de Vedkommende sig allerunderda. nigst have at rette.

Givet paa Vort Slot Frederiksberg, d. 20. October 1810. Under Vor Kongelige Haand og Seigl Frederik R.

Moltke.

Rosenstand Goiske.

Det er interessant at lægge Mærke til, at Regeringen den Gang tog Skridtet helt ud og belagde ogsaa de indenfor Landets Grænser værende Beholdninger, der allerede een Gang var fortoldede, med det halve af den nye Afgift. Saa langt vovede man sig ikke denne Gang; Hamstrerne fik Lov at forsyne sig i Fred og Ro.

Men langt mere rigoristiske var dog de Forholdsregler, man tog over for den Tids samvittighedsløse Storspekulanter. Den 6te November 1810 udsendtes to Forordninger, der tog Sigte dels paa Vekselspekulationen, dels paa den ovenfor omtalte Udførsel til Udlandet af dansk Valuta. Den første lyder saaledes:

"Vi Frederik den Siette, af Guds Naade .... etc. Gjøre vitterligt: At, da vi have overbevist $O$ s om, at et vidt udstrakt Misbrug af Vexel-Credit i Dansk Courant, utilladeligen er bleven benyttet som et Hjelpemiddel til at drive og fortsætte en for Kongerigernes Pengevæsen højst fordærvelig Agiotage; saa have Vi allernaadigst fundet for godt at anordne følgende:

$\S 1$.

Det skal, fra denne Forordnings Bekjendtgjørelse og indtil videre, aldeles være Enhver i Vore Riger 
forbudet, at trassere, remittere, præsentere, acceptere, indossere, sælge, købe, discontere eller udbetale nogen Vexel paa Dansk Courant, som, hvad enten den lyder a dato eller paa sigt, er stilet at betales efter længere Tids Forløb end 8te Dage fra Acceptations-Dagen at regne. Og skulle saadanne Vexler derhos med næste Post efterat de ere udstete afsendes til Acceptation.

\section{§2.}

Ovenstaaende Bestemmelser ere at anvende, saavel, naar Vexler lydende paa Dansk Courant vorde udstedte til at betales her i Riget, som og, naar de udgives at betales paa fremmede Steder.

\section{§ 3 .}

Vexler paa Dansk Courant, hvad enten de stiles paa 8 Dage eller kortere Tid, tilstaaes ikkun trende Løbedage.

$\S 4$.

Enhver, som imod denne Anordnings Forskrift trasserer, remitterer, præsenterer, accepterer, indosserer, sælger, køber, disconterer eller udbetaler nogen Vexel, bør erlægge en Mulct, af 10 Procento af Vexelens Beløb til Vor Casse.

\section{$\S 5$.}

Desuden skal den utilladelige Vexels paalydende Sum være Vor Casse hjemfalden.

$\S 6$.

Er Vexelen accepteret, bliver Søgsmaalet til Beløbets Confiscation at anlægge mod Acceptanten; $i$ andet Fald mod Trassenten. 


\section{\$ 7.}

Kan Vexelens Beløb ej hos nogen af disse erholdes, da bør enhver, som ellers efter Vexelret var forpligtet, for samme staa til Ansvar.

§8.

Den Mægler, som kjøber eller sælger nogen utilladelig Vexel, (§ 1.) skal, foruden at erlægge den i $\$$ bestemte Mulct af 10 Procento, tillige have sin Bevilling forbrudt.

\section{$\S 9$.}

De Forbudde, som indeholdes i denne Anordning, skulle ikke være gjældende for saadanne Vexler paa Dansk Courant, hvis Forfaldstid indtræffer før end den 15. December d. A., for saavidt de ere stilede paa Sigt, eller før end den 15de Januarii 1811, for saa vidt de ere trukne a dato.

\section{$\S 10$.}

Vexler paa Sigt, hvis Forfaldstid indtræffer ef te $r$ den 15. December d. A., og Vexler a Dato, hvis Forfaldstid indtræfer ef t e r den 15. Januarii 1811, skulle, saafremt de findes trukne fra Stæder, hvor denne Anordning ej ved deres Udstedelse kunde være bekjendt, anmeldes for Øvrigheden paa det Sted, hvor Acceptanten boer. Naar Øvrigheden verl sin Paategning har bevidnet den skeete Anmeldelse, bør den saaledes paategnede Vexel af Ihændehaveren deponeres hos den Vexelkommittee, som dertii af Vort Finantscollegio bemyndiges; paa det at saadanne Vexler, imellem Accepten og Forfaldstiden, ef skulle benyttes til Pengeomsætning.

$\S 11$.

Forsømmes den (i § 10) befalede Anmeldelse, eller undlader Ihændehaveren af Vexelen at deponere 
samme, da straffes han med at bøde til Vor Casse 10 procento af Vexelens Beløb.

$\S 12$.

Vexler lydende paa Species, Banko, eller anden Valuta end Dansk Courant, kunne ubehindret trasseres, indoseres, præsenteres, accepteres, sælges, kjøbes, disconteres og betales efter deres Værd, uagtet de ere udstædte paa længere Tid, end ovenmeldte 8 Dage ( $\$ 1$ ); og bliver, i Henseende til disse, $\mathbf{i}$ alle Maader at forholde efter de om Vexler forhen udgivne Anordninger.

\section{§ 13.}

Naar en Vexel, der lyder paa Species, er forfalden til Betaling i Vore Kongeriger, da skal det modtages som fuld og god Betaling, naar Acceptanten indfrier den med Dansk Courant, efter bestemt Cours, nemlig: i Kjøbenhavn efter den Cours, som af den Danske og Norske Speciesbank var noteret den sidste Dag for Forfaldstiden; og udenfor Kjøbenhavn efter den Cours, som af bemeldte Bank var noteret, da den for Forfaldstiden sidst ankomne Post afgik fra Kjøbenhavn.

\section{\$14.}

I Henseende til alle i denne Anordning ikke udtrykkeligen benævnte Punkter, Vexler betræffende, bliver at forholde efter hvad som hidtil har fundet sted.

Hvorefter alle Vedkommende sig allerunderdanigst have at rette. Givet $i$ Vor Kongelige Residentsstad Kjøbenhavn, den 6. November 1810.

Under Vor Kongelige Haand og Seigl Frederiks $R$. 
II.

Det var en ret indviklet Møntordning, vi havde $i$ Danmark i det 18. Aarhundrede, dengang Kurantmønten var Danmarks Rigsmønt. I 1695 havde Danmark indført den lybske Kurantfod, efter hvilken der gik 11/3 Kurantdaler paa Marken fin. 136 Rigsdaler Kurant var lig med 111 Speciedaler. Men efterhaanden forringedes ved denne Indførelse Speciedalernes Metalværdi, og i Løbet af de følgende Aar, indtil omkring 1710, dalede Værdien saa meget, at Kurantdaleren nu kun var en slet og ret Regningsenhed, et Udtryk for en vis Mangde Smaamont. I 1710 paabegyndtes en Udmøntning af 12-Skillinger af ringere Værdi, saaledes at der nu gik $106^{2} / 3$ Stk., der var lig med 13\% Rigsdaler Kurant, paa Marken fin. Imidlertid hjalp det altsammen intet. Kursen blev stadig ringere og ringere, og da Hamborg saa truede med at forbyde Brugen af dansk Kurant, maatte deres Værdi i 1726 nedsættes til 10 Skilling. Nu gik det saa slideligt, indtil man paa Christian den Sjettes Tid endelig besluttede sig til ved en ny Udmøntning at overholde Kurantfoden. Det hjalp - for en Tid. 1736 oprettedes en Kurantbank, der fik Lov at udstede Sedler, der skulde kunne indløses med Kurantmønt. Uden at Sedlerne iøvrigt tabte $i$ Kurs blev Indløsningen suspenderet fra $1745-1747$, men da man 10 Aar senere gentog Eksperimentet, blev Bankens Sedler fra den Tid af uindløselige Papirspenge.

Det gik nu stadig mere og mere nedad med Kursen. Krigen i 1801 og senere i 1807 kom og gjorde selvfølgelig ikke Sagen bedre, og i 1810 var Stillingen derfor saaledes, at man matte gribe til 
de kraftige Modforholdsregler, som omtaltes i forrige Artikel.

Samme Dag - den 6te November 1810 - som Forordningen udsendtes "angaaende hvorledes med Vexler paa dansk Courant, og med Betaling af Vexler, som lyder paa Species, indtil videre forholdes", udsendte man ogsaa en Forordning "angaaende Forsendelse af Dansk Courant Banksedler, og andre paa Courant lydende Repræsentativer«. Den lød som følger:

"Vi Frederik d. Siette, af Guds Naade .... etc. Giøre vitterligt: Vi have allernaadigst fundet for godt at anordne følgende.

\& 1.

Danske Courant-Banksedler, saavel som de paa Skatkammer-Afdragsfonden udstædte Repræsentativer, lydende paa dansk Courant, maa herefter ej paa anden Maade forsendes fra vore Kongeriger til Hertugdømmene eller Udlandet, end med Pakkeposterne.

\section{\& 2.}

Saa maa ej heller nogen Rejsende føre saadanne Banksedler eller Repræsentativer med sig til Steder, som ere beliggende sydligere end Hadersleben og Tondern.

\section{$\$ 3$.}

Enhver, som herimod forseer sig, skal have den Sun, han udsender eller fører med sig, forbrudt til Vor Casse, og desuden erlægge ligesaa meget som dens Beløb i Mulct.

$$
\$ 4 .
$$

Af denne Mulct tilfalder den halve Deel Vor 
Casse, og den halve Deel den, som beviisligen angiver eller opdager dette Forbuds Overtrædelse.

\section{$\S 5$.}

Dog skal det være Skippere og Søefarende, som til Vore Hertugdomme ankomme, umiddelbart fra noget Sted i Vore Kongeriger, uformeent at medbringe forommeldte Banksedler eller Repræsentativer til det Sted i Hertugdommene, hvor de først lande.

$\$ 6$.

For Rejsende fra Kongerigerne til Hertugdommene skal den Anstalt vorde føjet, at disses medhavende danske Banksedler eller Repræsentativer, paa deres Forlangende kunne paa Amtsstuen i Hadersleben og Tondern modtages in Deposito.

Ligeledes kunne de Rejsende ved deres Ankomst til Færgestæderne, nedlægge de medhavende Summer i nærmeste Amtsstue eller Kæmnercasse.

Hvorefter alle Vedkommende sig allerunderdanigst have at rette. Givet i Vor Kongelige Residentsstad Kiøbenhavn, den 6te November 1810.

Under Vor Kongelige Haand og Seigl Frederik R.

Denne tydeligt udtalte Vilje fra Regeringens Side til ved alle tænkelige Midler at forsøge en Ophjælpning af Valutaen og en Begrænsning af den for Landet saa ødelæggende Storspekulation $i$ de dalende Konjunkturer, førte til, at der Aaret efter atter kom et nyt Forbud, - denne Gang en Forordning indeholdende "yderligere Bestemmelser til at sætte Grandser for Agiotagen«. 
Vi Frederik den Siet te, af Guds Na a d e .... etc., Gjøre vitterligt:

Ved ufravendt Opmærksomhed paa den Fremgangsmaade og de Midler som til Forringelse af de danske Banksedlers Vardi benyttes, for det meste af saadanne Personer, der enten misledes af utidis Engstelighed eller drives af lastværdig Egenfordeel; have Vi overbevist $O$ s om Nødvendigheden af yderligere Bestemmelser til at sætte Grændser for Agiota. gens fordærvelige Følger; thi byde og befale Vi:

\section{$\S 1$.}

Ligesom det ved Forordningen af 25. May 1804 om det stemplede Papirs Brug, er i Almindelighed forbudet at udstæde eller modtage paa ustemplet Papir noget Document som lyder paa Penge eller Penges Værd, saaledes skal det og i Særdeleshed være enhver i Vore Riger og Lande aldeles forbudet at udstede eller modtage paa ustemplet Papir det Slags Gieldsbeviser, som under Navn af Anfordringssedler $i$ den senere Tid er fort i Brug imellem Handlende og Andre.

\section{$\S 2$.}

Anfordringssedler, eller Gieldsbeviser, hvorved Debitor forpligter sig til paa Creditors Anfordring at betale en skyldig værende Sum, ere herefter allene tiladelige under Iagttagelse af følgende Bestemmelser:

a) De skrives paa stemplet Papiir af 2den Klasse efter Forordningen af 25de May $1804 \$ 3$.

b) De skulle straks ved Udstædelsen dateres, og gielde ikkuns 4 Maaneder fra Udstædelsens Datum.

c) De skulle lyde paa Navn og ikke paa Ihændehaver. 
d) De maa ei endosseres eller transporteres uden paa særskilt stemplet Papiir, og maa saadan Transport ej heller lyde paa Ihændehaver.

\section{\$ 3.}

Anviisninger eller Assignationer maae herefter som hidtil ifølge Forordningen af 25de May $1804 \$ 8$, skrives paa ustemplet Papiir, dog allene under følgende Indskrænkninger:

a) Udenbyes Anvisninger eller Assignationer, hvilke for Fremtiden saaledes som indenbyes maa forsynes med Accept, skulle lyde paa at betales strax paa Sigt eller a vista.

b) Anvieninger eller Assignationer paa Udstaderens Handelsfirma eller paa dennes Associe ere ulovlige.

\$ 4.

Vexler lydende paa dansk Courant, som herefter trækkes paa Kiøbenhavn, enten fra fremmed Sted eller fra noget Sted i Vore Hertugdomme sydligere end Hadersleben og Tondern, eller og fra noget andet indenlandsk Sted for fremmed Regning, maa allene udstædes a vista eller til at betales strax paa Sigt.

\section{5.}

Overtrædelser af de forestaaende Forskrivter (\$§ 2,3, 4) straffes med Confiscation af den ulovlige Anfordringsseddels, Anviisnings, Assignations eller Vexels paalydende Sum, og enhver Deeltager i saadan Overtrædelse straffes desuden med Mulct af 10 Procent, i Analogie med Vor Forordning af 6te November 1810 .

\section{$\S 6$.}

Ingen i Vore Riger maa under Confiskationsstraf pantsatte eller til haandfaaet Pant modtage 
Guld og Sølv i Barrer, Species eller Speciessedler. Mønter være sig indenlandske eller fremmede, fremmede Banksedler eller Vexler, der lyde paa anden Pengesort end dansk Courant.

\section{$\$ 7$.}

Panter af ovennævnte Beskaffenhed, som førend denne Vor Anordning maatte være satte eller modtagne, og ikke inden 14 Dage fra sammes Bekiendtgiørelse af indiries, skulle enten af Panthaveren eller Pantsætteren uopholdeligen anmeldes til Førstnævntes Øvrighed, hvilken det da skal paaligge, at foranstalte Pantet efter lovlig Omgang ved Auction bortsolgt. Forsømmes den heri befalede Anmeldelse til Øvrigheden, da indtræder Confiscationsstraffen.

$\S 8$.

Vexler lydende paa anden Pengesort end dansk Courant, maa ikke af nogen i Vore Riger disconteres i dansk Courant, under Confiscationsstraf.

s 9 .

Forpligtelser, hvorefter contraheres om at levere og modtage Hamborger Banco, grov Courant, Species eller Speciessedler, fremmede Penge, være sig Courant eller i Vexler, eller Guld og Sølv i Barrer, maae af ingen i Vore Riger indgaaes eller afsluttes paa anden Maade, end at det Omcontraherede skal leve. res og modtages strax eller i det seneste inden 3 Dage; $i$ andet Fald have begge de Contraherende forbrudt til Confiscation det giensidigen Omcontraheredes fulde Beløb.

\section{$\S 10$.}

Forpligtelser stridende mod ovenanførte Bestemmelse, som maatte være indgaaede førend denne Vor 
Anordning, og som Contrahenterne ikke kunne forenes om at hæve, skulle disse være pligtige inden 14 Dage fra Bekiendtgørelsen heraf at anmelde for $\emptyset \mathrm{v}-$ righeden, hvilken det paaligger, med Paategning om den i rette Tid skeete Anmeldelse at forsyne Contracten, samt dernæst at indsende rigtig Gienpart af samme til Vort Cancellie, som derover har allerunderdanigst at indhente Vor nærmere Allerhøieste Bestemmelse. Forsømmes den heri befalede Anmeldelse til Øvrigheden, da blive de skyldige Contrahentere at straffe i Overensstemmelse med næstforegaaende \&.

\section{\$11.}

Mæglere, som maatte deeltage i Transactioner stridende mod denne Vor Anordning, blive foruden Mulct af 10 Procent af Transactionens Beløb at straffe med Deres Bestillings Fortabelse.

$\S 12$.

Skifteforvaltere og Skiftecommissarier, som ved Behandlingen af Stervboer og Opbudsboer maatte komme til Kundskab om Transactioner stridende mod denne Vor Anordning, paaligger det ufortøvet derom at giøre behørig Anmeldelse. I Forsømmelses Tilfælde blive de at drage til Ansvar for det Beløb, der ved Confiscation vilde have været Vor Casse hjemfalden, samt desuden at ansee med Mulct af 100 Rdlr. til 1000 Rdlr. efter Sagens Beskaffenhed.

813.

I Alle de Tilfælde, hvor nogen Overtrædelse af denne Vor Anordning ved Angiver opdages, nyder denne Halvdelen af den Vor Casse hjemfaldende Confiscationssum. 
Hvorefter alle Vedkommende sig allerunderdanigst have at rette.

Givet paa Vort Slot Frederiksberg, den 26de September 1811.

Under Vor Kongelige Haand og Seigl Frederik R.

Kaas.

Cold. Knudsen. Bülow. Monrad.

Endskønt Regeringen gik saa voldsomt frem, dalede Kurantens Værdi dog stadig, - der er jo et gammelt Ord der siger, at hvor Vorherre laver en Lov, der laver Fanden en Bagdør, hvorigennem Loven kan omgaaes. Om det nu var Grunden her, skal være usagt, - man skulde paa Forhaand synes, at alle saadanne "Bagdøre" var blevet forsvarligt lukkede og laasede ved de skrappe Mulkter og Confiskationsstraffene, og hvem vidste sig vel nogensinde sikker, Angiveri var jo et lønnende Erhverv. Men hvordan det nu end hang sammen, - sandsynligvis var Grunden, at Kurantens Værdiforringelse allerede var $f$ or la ng t f em skreden, da Stabiliseringsbestræbelserne begyndte, eet er givet: Kurantmøntens Rolle var udspillet. Den sov ind i 1812 og vaagnede aldrig mere. 